\title{
ESCOLAS ITALIANAS NO RIO GRANDE DO SUL: PESQUISAS E DOCUMENTOS
}

\section{RESENHA}

RECH, G. L.; LUCHESE, T. A. Escolas italianas no Rio Grande do Sul: pesquisas e documentos. Caxias do Sul, EDUCS, 2018.

\section{Cassiane Curtarelli Fernandes*}

lattes.cnpq.br/50882561399455535

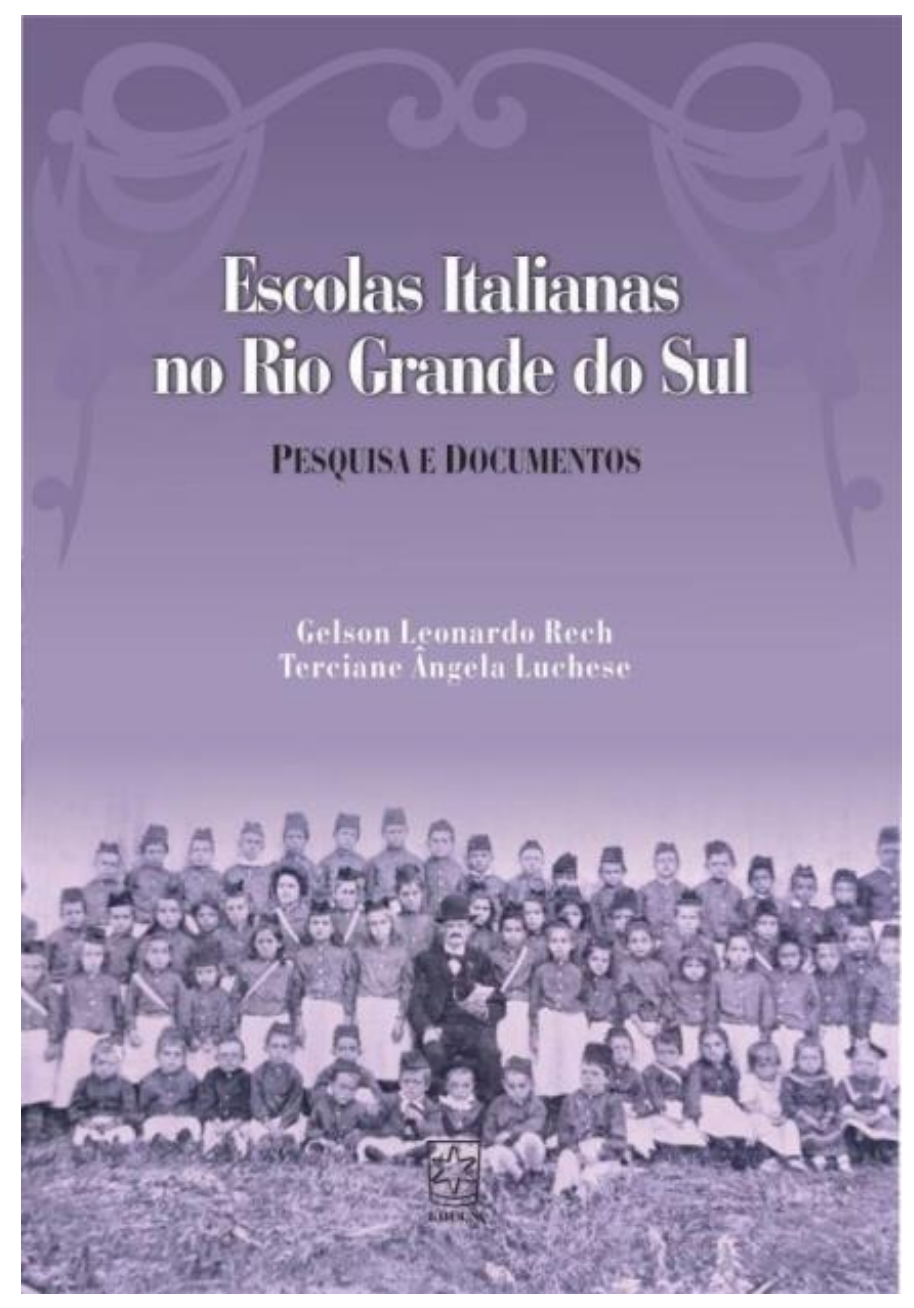

Escolas italianas no Rio Grande do Sul: pesquisas e documentos, é o título da obra composta pelos pesquisadores Gelson Leonardo Rech e Terciane Ângela Luchese, publicada em 2018, pela editora EDUCS. O escrito é fruto da continuidade das pesquisas empreendidas pelos autores em torno dos processos educativos entre imigrantes italianos e seus descendentes no Rio Grande do Sul, assim como dos diálogos mantidos no Grupo de Pesquisa História da Educação,

\footnotetext{
* Doutoranda em Educação pela Universidade de Caxias do Sul, UCS (Brasil).
} Contato: cassianecfernandes@gmail.com. 
Imigração e Memória (GRUPHEIM) da Universidade de Caxias do $\mathrm{Sul} / \mathrm{RS}$.

De uma forma acessível, Gelson e Terciane partilham seus empreendimentos de pesquisa com o público interessado na temática da imigração italiana no estado gaúcho. As páginas, escritas a quatro mãos, reúnem três movimentos: narram uma história das escolas italiano no estado, apresentam uma reflexão metodológica e transcrevem documentos primários, alguns até então inéditos para a área da História da Educação.

O livro, organizado em três capítulos, inicia com prefácio elaborado pelo Prof. Dr. Elomar Antonio Callegaro Tambara, que aborda brevemente o processo imigratório italiano no Rio Grande do Sul. Em seguida, há uma apresentação da obra pelos autores, desejando que "a leitura das páginas que seguem possa inspirar outros investigadores e interessados pela temática a pensarem os processos educativos étnicos como uma importante singularidade no contexto brasileiro" (RECH; LUCHESE, 2018, p. 12).

No primeiro capítulo intitulado O processo escolar entre imigrantes italianos e descendentes no Rio Grande do Sul (1875-1938), os pesquisadores apresentam os resultados das investigações realizadas nos últimos anos acerca do processo escolar entre imigrantes e descendentes de italianos no estado, nos anos finais do século XIX, mais especificamente nas colônias da Serra gaúcha e na capital Porto Alegre.

O texto inicia com um panorama histórico acerca do processo imigratório-italiano no estado, apontando brevemente as causas da imigração, o interesse do governo brasileiro no fenômeno migratório, assim como a formação das diversas colônias estabelecidas a partir de 1870. Em seguida, apresenta o contexto educacional do Rio Grande do Sul entre o século XIX e o XX. Depois, direciona o olhar para o processo escolar entre imigrantes italianos e os seus descendentes, apontando que "diversas foram as iniciativas dos imigrantes na organização de escolas" (RECH; LUCHESE, 2018, p. 25). Entre estas iniciativas, os pesquisadores destacam as escolas étnico-comunitárias 
rurais, as escolas étnico-comunitárias mantidas por Associações de Mútuo Socorro e as escolas ligadas a congregações religiosas. Ainda, ressaltam que às escolas públicas - isoladas, grupos escolares e colégios elementares, foram também requisitadas pelos imigrantes. No entanto, ressaltam que:

\begin{abstract}
Essa escola frequentada pelos imigrantes, seus filhos e netos, mesmo sendo pública, era marcada por elementos étnicos. O próprio prédio escolar e a terra onde estava localizada, muitas vezes, foram doados pela comunidade, assim como os móveis. As comunidades frequentemente interferiam na nomeação e/ou indicação do professor, como averiguou Luchese (2007). As práticas pedagógicas e o sotaque dialetal, bem como outros elementos culturais étnicos, marcavam presença nas salas de aula. (RECH; LUCHESE, 2018, p. 37).
\end{abstract}

Após, os autores apresentam algumas iniciativas de escolarização tendo como pano de fundo à capital Porto Alegre. Assim, evidenciam a organização do Instituto Médio Ítalo-Brasileiro que funcionou como um colégio-internato, entre os anos de 1917 a 1930, fundado pelo Professor Augusto Menegatti e sua esposa Linda Menegatti, como também a reorganização das escolas étnicas na capital.

Concluem este primeiro capítulo elencando algumas dificuldades encontradas para se manter as iniciativas das escolas étnico-comunitárias, bem como as influências do governo fascista de Mussolini a partir de 1922, sobre as escolas étnicas italianas e a preferência dos imigrantes e descendentes pela escola pública.

Análise documental histórica: considerações metodológicas sobre a história da escola entre imigrantes italianos e seus descendentes é o título do segundo capítulo organizado pelos autores, tendo como objetivo compartilhar considerações sobre os caminhos teóricos e metodológicos de suas investigações (RECH; LUCHESE, 2018). Sendo assim, destacam a utilização do aporte teórico-metodológico da História Cultural, a importância de tomar os documentos como monumentos nas pesquisas e o trabalho com a análise documental organização e interpretação dos dados.

Nesta segunda parte do livro, os autores partilham com os demais pesquisadores da área, seis preocupações necessárias no 
trabalho com a análise de documentos textuais, a saber: 1) as condições de produção do documento; 2) os procedimentos internos; 3) as condições de circulação do documento; 4) a materialidade do documento; 5) a apropriação; 6) a preservação. Da mesma forma, demarcam a importância do cruzamento das fontes selecionadas nas pesquisas, a diversificação das mesmas - textuais, orais e iconográficas, o diálogo com a teoria e o cuidado com as referências de localização dos vestígios com compõe o corpus documental da investigação. Desse processo, emerge "a tessitura da escrita", nas palavras de Rech e Luchese (2018, p. 74). Para ambos:

\begin{abstract}
Nesse jogo de vida e morte, de passado e presente, de documentos e monumentos, não podemos esquecer que as narrativas históricas da educação, derivadas das pesquisas que produzimos, são resultados de trabalho com questões de pesquisa possíveis no tempo em que vivemos e que, para respondê-las, construímos um corpus empírico. Destarte, indícios, rastros, sinais que são ordenados, montados, questionados na análise, na inter-relação e contextualização que procedemos para escrever história, escrever um possível sobre o passado educacional, reconhecendo a precariedade e a necessidade de revisitar documentos, munidos por novos questionamentos. É o movimento constante da pesquisa. (RECH; LUCHESE, 2018, p. 77).
\end{abstract}

No terceiro e último capítulo denominado Repertórios documentais, Gelson e Terciane, de forma generosa, compartilham quatro documentos que auxiliam na compreensão da história da escola entre imigrantes italianos e descendentes no estado do Rio Grande do Sul.

O primeiro documento apresentado pelos autores é um relatório elaborado pelo italiano Ranieri Venerosi Pesciolini, que em visita aos estados do Rio Grande do Sul, do Paraná e de Santa Catarina, escreve no ano de 1912, sobre a vida nas colônias italianas, incluindo um tópico sobre a as escolas e a instrução. A segunda fonte também é um relatório e foi produzida em 1923, pelo professor italiano Vittore Alemanni que escreve sobre as escolas italianas no Brasil. O terceiro documento é um recorte do texto apresentado no livro Cinquantenario della colonizzazione italiana nel Rio Grande del Sud (1875-1925) por Benvenuto Crocetta em 1925, onde o mesmo compõe um pequeno escrito sobre as escolas. O último vestígio é uma carta de Celeste 
Gobbato, intendente de Caxias do Sul, endereçada a Benito Mussolini, no ano de 1927, "pedindo a intervenção do Duce para que os padres salesianos implantassem um ginásio em Caxias do Sul” (RECH; LUCHESE, 2018, p. 150). Os documentos disponibilizados são apresentados na sua versão original em língua italiana e acompanham as respectivas traduções realizadas pelos autores do livro.

A obra escrita por Rech e Luchese (2018) é uma importante contribuição para os estudos historiográficos em torno dos processos educativos nas colônias de imigrantes e descendentes de italianos. A partir das investigações dos autores é possível perceber que a escola foi alvo de desejo e de interesse por parte das famílias italianas desde os anos iniciais de formação dos núcleos coloniais.

Sendo assim, além de compartilhar os conhecimentos construídos sobre a temática do livro, os autores dividem com os jovens pesquisadores da área da História da Educação os seus modos de trabalhar com a análise documental e narrar uma história. Refletem acerca do problema de pesquisa e do uso de documentos, apontam autores dentro do referencial teórico-metodológico da História Cultural e sugerem caminhos para a metodologia da análise documental. Ao final, ainda nos brindam com a reprodução de quatro documentos que tratam sobre a escolarização.

Escolas italianas no Rio Grande do Sul: pesquisas e documentos é uma publicação inspiradora e que merece nossa atenção. 